\title{
INTRINSIC FACTORS IN THE DEVELOPMENT OF SPINAL DEFORMITIES WITH PARALYSIS
}

\author{
By G. M. Bedbrook, O.B.E., M.S., F.R.C.S., F.R.A.C.S. \\ Department of Paraplegia, Royal Perth Hospital, Perth, Western Australia
}

IN I965, Kilfoyle, Foley and Norton reported a series of I04 cases of spinal and pelvic deformity in adolescent paraplegics. Since that time a study of similar cases which have come into the Spinal Unit of Royal Perth Hospital has been commenced. However, such cases are not admitted until the age of I 4 years, by which time many of the deformities have already been well developed. During the past three years 3 I cases of spinal deformity after paraplegia have been studied, not yet all completely. Some have had treatment attempted. In this paper, the intrinsic factors associated with the development of such spinal deformities will be considered. Extrinsic factors are responsible for the curve patterns in varying degrees. As these are of course well known they will not be discussed; they include unequal and severe muscle paralysis, hip contractures, spinal spasm, congenital vertebral deformity, lack of normal postural forces, the use of wheelchairs for long periods of time. Fundamentally the intrinsic factors which are responsible for severe deformities are four:

I. The alteration of growth associated with vertebral deformity after fracture (Case Nos. I, 2 and 3).

2. The intrinsic effect of posture on vertebral curvature and structure (Case No. 4).

3. Destruction of vertebral bodies by vertebral disease (Case No. 5).

4. The use of external radiation, e.g. deep X-ray therapy, in spinal cord or column tumours.

Deformities seen include:

A. Lordosis. This is the more common. As a primary deformity it occurs more commonly in the lower neurological lesions and is exemplified in this group of cases by those cases with lower motor neurone lesions (with and without vertebral anomalies) (Kilfoyle et al., I965).

B. Scoliosis. This is evenly distributed at all levels of spinal cord disability.

C. Kyphosis. This is a deformity related to trauma or infection and is particularly pertinent to the material to be considered. This as already indicated by Moe (I968), Hodgson (1963) and others is by far the most serious deformity encountered being occasionally associated with deterioration of paralysis.

No attempt in this paper will be made to discuss the problem of spinal deformity and respiratory function. 


\section{INTRINSIC FACTORS}

$A$. Growth. A vertebral body grows longitudinally by true epiphyseal plates as shown by Bick in 1950, and commented on by Roaf (1960). The vertebral ring is an apophysis rather than an epiphysis and takes little part in the longitudinal growth. In such longitudinal growth the vertebral body grows in much the same way as the metaphysis and diaphysis of a long bone. Longitudinal growth is however only one dimension of growth, for the bodies expand and grow both sagittally, cephalically and laterally. Unequal growth can cause deformity. In our present series three cases have been affected by pathology which has caused or can cause growth deformity over a period of some years, one with catastrophic development of further paralysis.

Case No. I. J. L., male, aged II, admitted 26 December 196I with an almost complete quadriparesis below $\mathrm{C}_{4}$. X-rays showed crush fractures of $\mathrm{C}_{3}-4$. By Io February I962 he had made an almost perfect recovery of both lower limbs with a residual central cord syndrome in his upper limbs, the left upper limb remaining almost completely paresed, his right upper limb being useful. Spasm developed in the right upper limb and various peripheral procedures were undertaken, e.g. division of the radial nerve, to help this complication. By March of 1962 he walked quite well with the aid of calipers, X-rays showing good alignment of the vertebral column with no displacement between $\mathrm{C} 2-3$. By April of 1962 severe deformity had occurred between $\mathrm{C}_{3}-4$ and $\mathrm{C}_{2}-3$. No alteration in his neurological picture occurred in 1963 , he continued to walk well with an incomplete Brown-Séquard lesion. In December 1963 spasm commenced to increase in both lower limbs, but by May of 1964 he still walked satisfactorily. No gross deterioration in his X-ray picture alignment took place between September 1963 and September 1965 although growth was apparent. In February of 1965 it was found that there was an increase in spasm in both lower limbs and increased paresis became obvious. His right upper limb also commenced to deteriorate. Careful review of his X-rays showed that there had been an increase in both growth and deformity, at the fracture site. Whilst not apparent in 1962, this alteration had become more apparent in 1962-3 and as growth had increased in 1965 there had been increasing deformity and size in the vertebral column with obvious damage to the epiphyseal plate of $\mathrm{C}_{3}$ and $\mathrm{C}_{4}$. A severe kyphos had developed which was clinically obvious. It was clear that the developing deformity had had an effect on the redevelopment of his quadriplesis. Operation was first advised early in 1965 when an 'osteotomy' at $\mathrm{C}_{3}$ was planned to straighten the neural canal, fusing the segment. This advice was persistently refused by patient and relatives until I967, when the patient's clinical condition deteriorated to complete tetraplegia. At this time operative interference was agreed to. It was considered that before any anterior surgery was undertaken that posterior surgery and laminectomy would be advisable to assess the cord position and commence the osteotomy. With great difficulty and with considerable extradural haemorrhage this was undertaken. The cord could not be demonstrated, being reduced to a thin layer of neural material. This was not interfered with for the fear of making this patient worse. With such a finding at operation it was felt that any anterior surgery could not give this patient any real improvement. He is thus left with an almost complete quadriplegia. Had this deformity not occurred, or been allowed to occur, there is no doubt that this man would not have developed his complete paralysis (fig. I). 


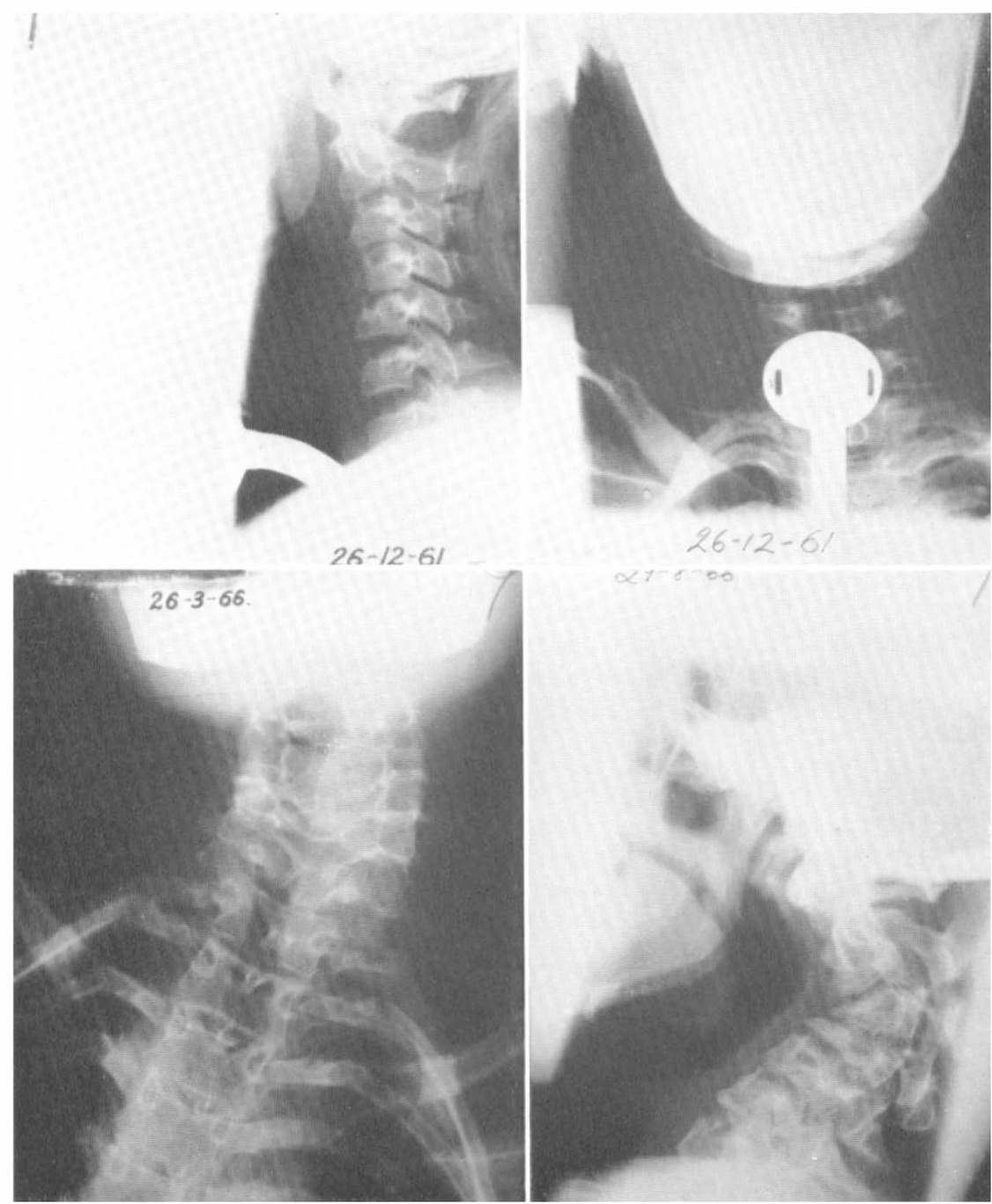

FIG. I

J. L., aged II, on admission 26 December I96I. By 29 August 1966 severe deformity.

Case No. 2. A girl, aged I3, admitted to hospital I July I968 subsequent to a trampoline injury in which she sustained a crush injury of $\mathrm{C}_{5}$ and $\mathrm{C} 6$ with subluxation of $\mathrm{C}_{4}-5$. On admission she was almost completely quadriplegic below the neurological level of C6, but has since regained power to become an incomplete Brown-Séquard lesion. After $4 \frac{1}{2}$ months there is no sign of bony union between the vertebral bodies. With the previous case in mind it was decided that this girl could develop a local kyphos, so an anterior spinal fusion between $\mathrm{C}_{4}$ and $\mathrm{C} 6$, to give a solid bony fusion, has been carried out. We hope this will prevent the development of such severe deformity and any neurological deterioration as in the previous case (fig. 2). 


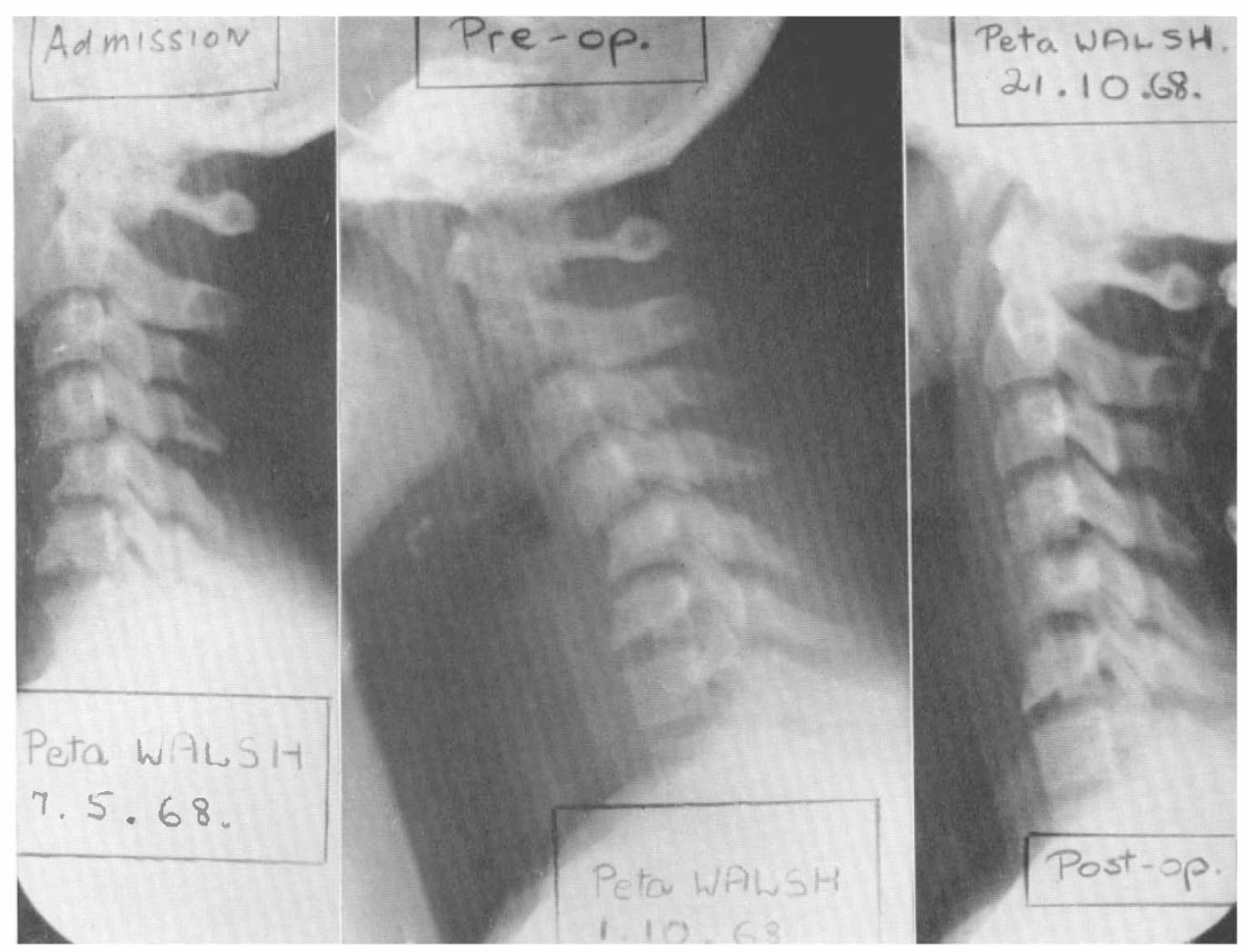

FIG. 2

P. W., girl aged I3. X-rays correction and fusion.

Case No. 3. R. B., aged I4, admitted I 6 January 1967 with complete dislocation of TI2 on LI with complete paraplegia below the level of L2 neurologically. Postural reduction of the fracture failed. Because of the gross dislocation, open reduction without any internal fixation was undertaken. Four months after his admission it was noticed that function had returned within each psoas to a power of 3. Opinion agreed that this boy would certainly develop flexion contractures of both hips, so psoas transfer was performed, the psoas being transplanted to the great trochanter. This was undertaken as a prophylactic measure against flexion contracture and spinal deformity. In the last I2 months, however, he has started to develop an early kyphos at the site of the vertebral injury. This is being watched with great interest to see whether deformity will develop further, for if it does there is a further indication for an anterior spinal fusion and to make this particular area of the vertebral column stable. It is doubtful at his age if this will become a serious matter (fig. 3).

Stabilisation of the vertebral deformity as soon as possible is, I believe, an important factor in the prevention of progressive spinal deformity, particularly kyphos in children injured at or before the age of II.

$B$. The Effect on Growth. By continually allowing patients to be nursed or managed in flexed positions, continued deformity and growth alteration will occur. 


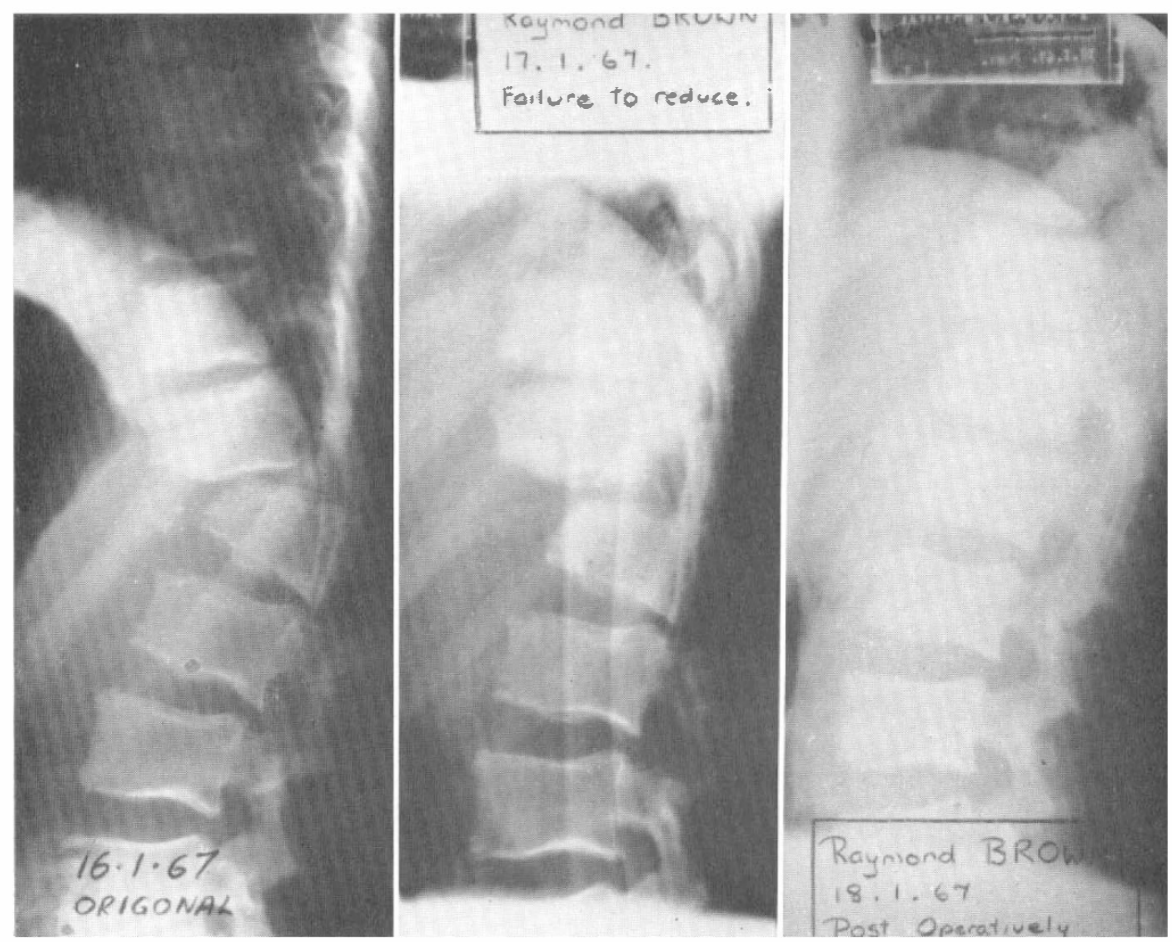

A

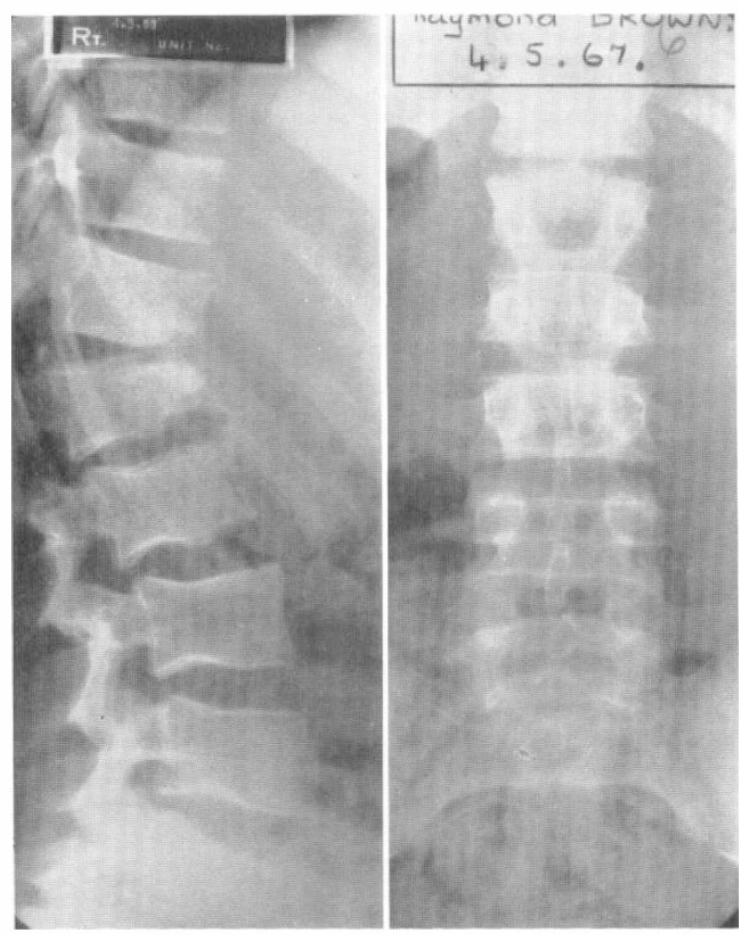

FIG. 3

R. B. A, Series pre- and post-operatively. B, X-ray 4 May 1967, deformity helped by growth. 
Case No. 4. W. K., a boy aged 4 years, who sustained a fracture-dislocation of $\mathrm{T}_{4-5}$ in 1944 , who was over many years not managed adequately, was allowed to sit up in a wheelchair, to curl up in bed, and never maintained any adequate posture. By I954 scoliosis occurred and after a period of another six years, just prior to death due to pyelonephritis, severe spinal deformity occurred, a lordo-scoliosis, which was largely due to extrinsic factors. At post-mortem gross lordo-scoliosis was demonstrated in this boy's spine. On careful dissection it was found that most of the deformity had occurred at the discs and only minimal deformity on the growth plates. Some effect can be seen from a study of the vertebral bodies. This case proves the very important point that

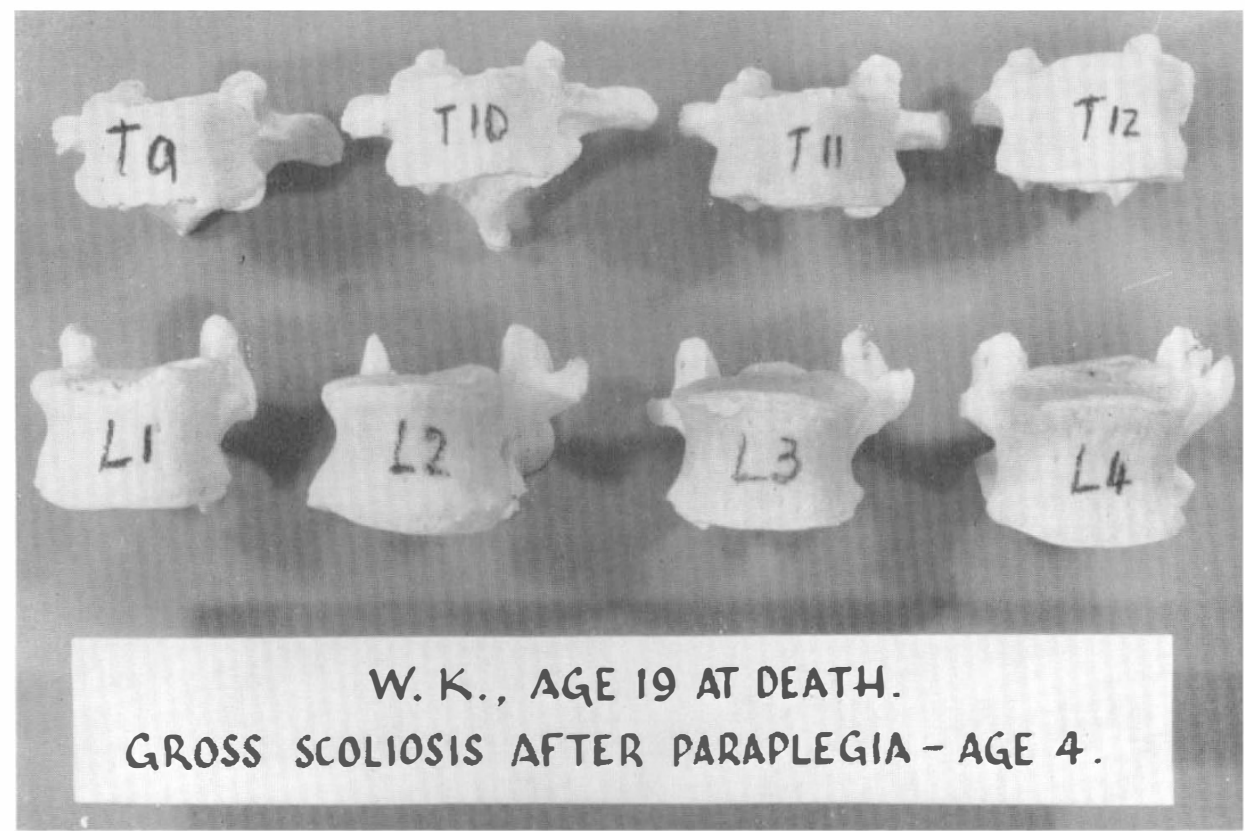

FIG. 4

Anterior views of vertebral bodies at post-mortem in severe lordo-scoliosis showing maximal effect on L2 and very little effect on other vertebrae.

most of the deformity in spinal curves occurs at the discs rather than the vertebral bodies in the pre-adolescent years. Although posture has some effect on the growth of the vertebral bodies, nevertheless the majority of the intrinsic changes occur at the disc, the disc deforming very much more easily (fig. 4).

C. Vertical Kyphos due to Destructive Disease. For example, vertebral kyphos after tuberculosis. No attempt will be made to describe this in detail. From the gross kypho-scoliotics that can occur in tuberculosis paraplegia may easily occur. Experience in this field in Australia is extremely limited; one case has been encountered.

Case No. 5. A girl, now aged i 8 years, who developed severe kyphos due to destructive tuberculosis and who then developed paraplegia, relieved by drainage of a paravertebral abscess. Her paraplegia recurred slowly later on with gross vertebral disease 
and was relieved by open anterior thoracic surgery with a wedge opening of the vertebral bodies and correction of the deformity according to the technique devised by Hodgson in Hong Kong.

D. External Radiation. Lastly, agents such as deep X-ray therapy have been known to affect and cause vertebral deformity after spinal cord tumours. Rare cases of this have been reported in the literature. When such a condition occurs in a child, one should remember the effect on growth of such therapy. We have no case in our series at the present time although we are watching one small girl who has had deep X-ray therapy for neuroblastoma of the spinal column with paraplegia, to see whether a spinal deformity will develop.

\section{TREATMENT}

With the knowledge of both intrinsic and extrinsic factors involved in spinal deformity, attempts to prevent the deformity rather than to cure it must be made. In this present small series now under review, some attempts at immediate management have been undertaken. Already developed curves may be corrected by:

(a) Spinal osteotomies (Io cases).

(b) The use of the Harrington rod procedure for correction (I case) (Harrington, I963).

Preventive measures must include:

(a) Minimising intrinsic factors.

(b) Maintenance of erect posture.

(c) Adequate bracing.

Once these spines start to deform, one must not wait for such to get worse before commencing therapy. Every effort should be made to prevent such an occurrence. In our own as yet limited experience only two cases have been treated with this view in mind. Another is being carefully watched.

Case No. 6. A boy of now I9 years of age, traumatic paraplegic at the age of 7 , who developed a severe collapsing spinal curve. At the age of I6 a Harrington rod procedure was used to maintain the curve at its pre-operative state, but did not give adequate correction of the curve. For subsequent six to nine months he wore an adequate Milwaukee brace very carefully fitted because of his paresis. I believe such braces to have an important place in preventive measures (figs 5, 6 and 7).

Case No. 7. A boy now aged I4, paralysis from the age of I I-transverse myelitis. He slowly started to develop a curve, but has been fitted adequately with a Milwaukee brace with the result that deterioration has been prevented. Such a brace has to be looked after very carefully because of the skin anaesthesia.

I believe that ultimately this boy will come to spinal fusion, but will come to such at the right age when growth has been completed, with the minimal of deformity and with a mobile curve. The brace is thus having three effects:

(a) Preventing the deformity from getting worse.

(b) Attempting to help its correction.

(c) Allowing maintenance of the mobility of the curve. 


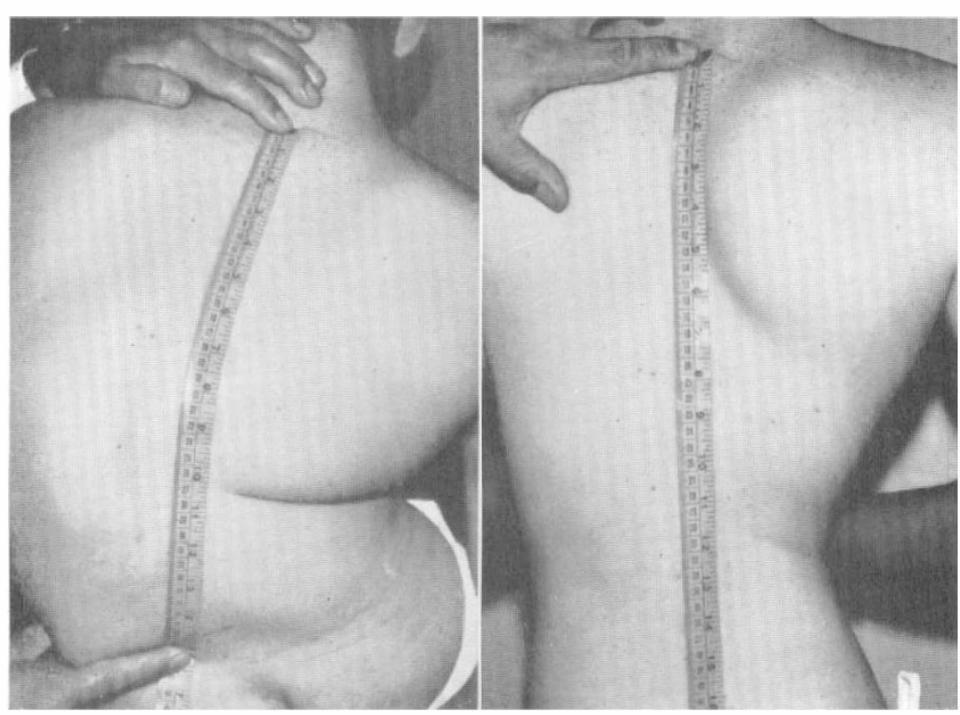

FIG. 5

A, Posterior view-sitting. B, On traction.

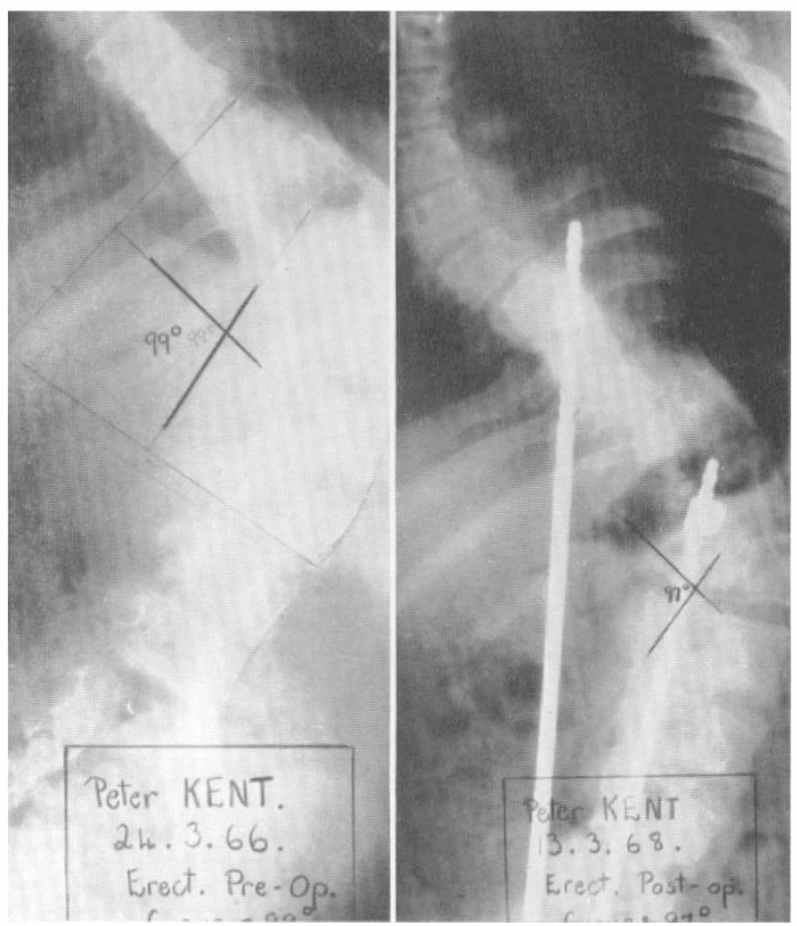

FIG. 6

Before treatment and after treatment. 


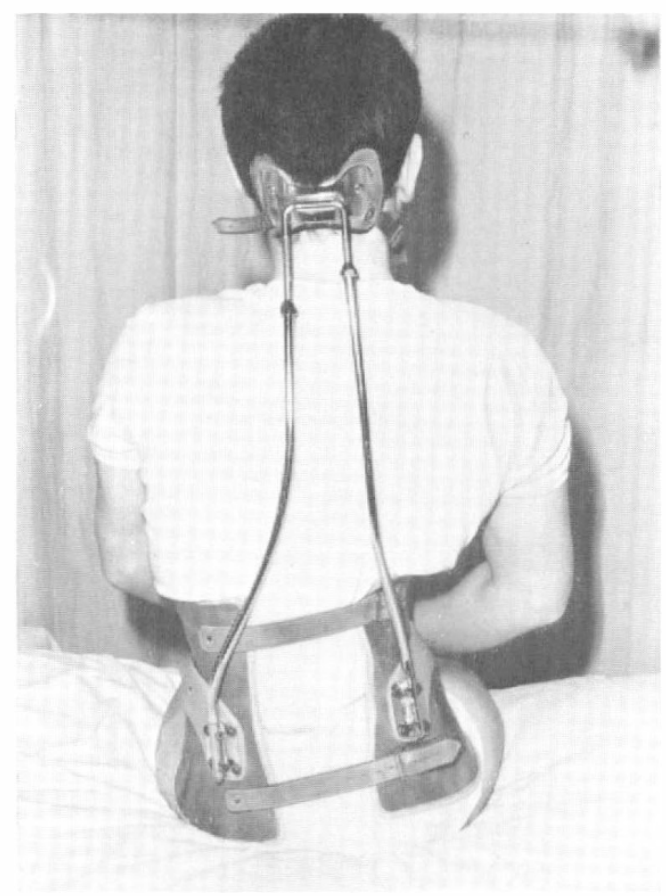

FIG. 7

Posterior view showing the Milwaukee brace.

\section{THE FUTURE}

New methods are being developed in the correction of such curves, and one such method has been developed by Mr. A. Dwyer of Sydney in Australia. The corrective measure is associated with the vertebral bodies, particularly taking into consideration the intrinsic pathology whereby most of the deformity occurs at the disc. At 15 or 16 years of age proper excision of the discs and curve correction using a special wire apposition technique is undertaken, the vertebral bodies being brought back into reasonable alignment after correction of the primary curve. Figure 8 illustrates the X-ray of a I5-year-old Chinese girl, paraplegic due to transverse myelitis who has had her curve corrected with this new device. This further has the advantage of allowing the child mobility soon after the accident and does not have the disadvantage of long-term immobilisation after the usual posterior or anterior spinal fusion.

\section{DISCUSSION}

There are thus many factors in the aetiology and development of such spinal deformities. These intrinsic factors are amongst those whose pathology must be understood before one can hope to prevent them entirely. Prevention will depend on an adequate consideration of both the major extrinsic factors which are well 

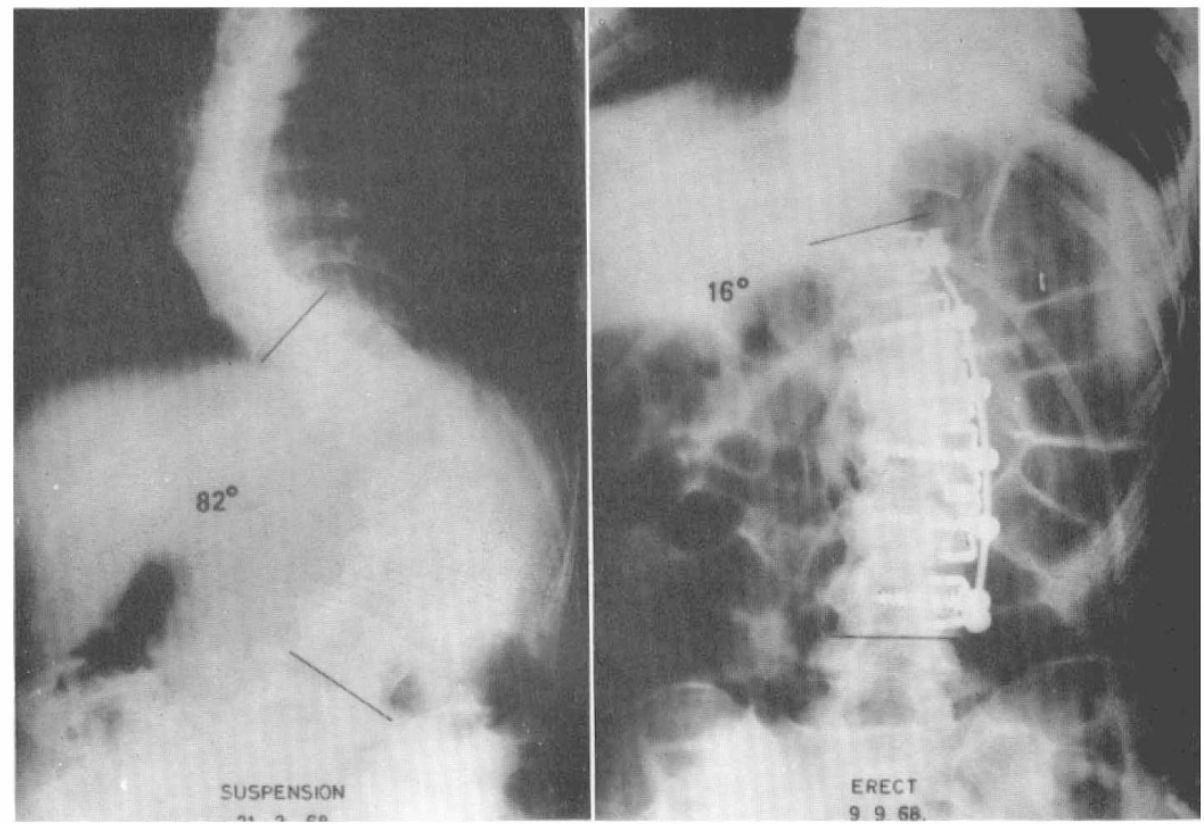

FIG. 8

New method of correction by Dwyer (Sydney) used on a paraplegic girl aged 15.

known and well recognised and the intrinsic factors which are perhaps not always recognised. Spinal osteotomy in young adults has been undertaken in this series Io times for the correction of such severe deformities with cosmetic and functional improvement and is particularly useful after spina bifida where severe deformity can of course occur immediately after birth (Sharrard, I968). Very little is known about the abnormalities in the spinal cord associated with vertebral abnormalities but these undoubtedly exist. Much more careful study is needed before one can be certain as to the ultimate prognosis, but certainly we are now sure from the researches of Moe and his team (1968), that kyphos carries with it a much worse prognosis than does scoliosis. The actual cause of paraplegia developing in scoliotics is unknown; many theories exist, including stretching of the cord, but actual facts are scarce as to the pathology behind such association (Kleinberg, I95I; McKenzie \& Dewar, 1949). As in the management of non-paralytic scoliotics, the curve in paraplegic deformities should be prevented and not cured.

\section{SUMMARY}

Intrinsic factors in spinal deformity after paraplegia have been considered; they include: alteration of growth after injury; the destruction of the vertebral body in the young child; the use of deep X-ray therapy in some vertebral condition; the effect of posture on the intrinsic mechanism of the spine, which is more deformative on the vertebral discs rather than on the vertebral bodies. Prevention is much better than cure; if the curve is becoming slowly worse then both extrinsic and 
intrinsic factors must be considered in the management of any patient with spinal deformity after such injury or disease. Treatment has been considered in a number of cases.

\title{
REFERENCES
}

Bick, E. M. (1950). Longitudinal growth of the human vertebra. F. Bone ft Surg. 32-A, 803 .

Harrington, P. R. (1963). Scoliosis in the growing spine. Pediat. Clins N. Am. 10, 225. Hodgson, A. R. (I965). Correction of fixed spinal curves. F. Bone ft Surg. 47-A, I22II227.

Kilfoyle, R. M., Foley, F. \& Norton, A. L. (1965). Spine and pelvic deformity in childhood and adolescent paraplegia: a study of I04 cases. F. Bone ft Surg. 42-A, 659-82. (I968) Personal Communication.

KleinBerg, S. (I95I). F. Bone ft Surg. 33-A, 225.

McKenzie, K. G. \& Dewar, F. P. (I949). F. Bone ft Surg. 31-B, I62.

MOE, J. B. (I968). A study of 234 patients with congenital scoliosis treated and untreated. F. Bone ft Surg. 50-A, I, I5.

RoAF, R. (I960). Vertebral growth and its mechanical control. Clinical and roentgenographic study. F. Bone ft Surg. 42-B, 40-59.

SHARRARD, W. J. W. (I968). Personal Communication.

\section{SPINAL DEFORMITY AFTER SPINAL CORD INJURY}

\author{
By Phillip Harris, F.R.C.S.E., F.R.C.P.E., F.R.C.S.(Glas.), F.R.S.E., \\ and W. J. Whatmore, M.B., Ch.B., F.R.C.S.E. \\ Department of Surgical Neurology, Royal Infirmary \\ and Western General Hospital, Edinburgh
}

SPINAL deformity may appear at the time of spinal cord injury or soon after this has occurred, or after a long interval. The assessment, investigation and management is determined by the individual features of each patient.

In this paper we do not intend to include a discussion of either penetrating spinal injuries or of spinal deformities resulting from muscle imbalance.

Some examples of spinal deformity after spinal cord injury will be given from an experience of patients seen in the Spinal Injuries Service in Edinburgh during the past 25 years.

$A$. Time of Occurrence of the Deformity. Usually the maximal displacement of the vertebral column occurs at the moment of injury, and damage to the neural and vascular elements appears at this time. Depending on the type of injury, the direction of the force and the anatomical region of the spine involved, the deformity of the vertebral column may be:

(I) A fixed, persistent deformity. This is seen, for example, in severe hyperflexion injuries of the cervical spine with dislocation and locked articular facets, with or without fracture of the articular processes.

(2) A latent or concealed deformity which can be present in certain patients with cervical injuries and only be revealed by careful radiological-movement studies. 